2. Михайлова Л.А, Мироненко Н.В., Коваленко Н.М. Желтая пятнистость пшеницы // Методические указания по изучению популяций возбудителя желтой пятнистости Pyrenophora tritici-repentis и устойчивости сортов. СПб.: ВИЗР, 2012. 56 с.

3. Тырышкин Л.Г., Колесова М. А. Септориоз колоса. Изучение генетических ресурсов зерновых культур по устойчивости к вредным организмам: метод. пособие. M.: PACXH, 2008. C. 185-186.

4. Lamari L, Bernier CC. Evalution of wheat lines and cultivars to tan spot [Perynophora tritici-repentis] based on lesion type. Can. J. Plant Sci.; 1989. 11(1): 49-56.

DOI 10.18699/GPB2020-36

\title{
Изучение особенностей культивирования и регенерации iv vitro диких видов картофеля
}

Колошина К.А. *, Иванова К.А., Герасимова С.В.

ФГБУН Институт ичитологии и генетики Сибирского отделения Российской академии наук, Новосибирск, Россия.

*e-mail: kristina.koloshina@yandex.ru

Целью данного исследования было изучение прочесса развития растений в культуре in vitro и влияния различных типов питательных сред на прочессы регенерачии дикого картофеля. Данные исследований по оптимальным условиям культивирования іп vitro растений картофеля и способности к регенерачии могут быть использованы для генетических исследований селекционного процесса при создании сортов с улучшенными признаками.

Ключевые слова: картофель, дикие виды, культивирование, регенерация.

\section{Study of the features of cultivation and in vitro regeneration of wild potato species}

Koloshina K. A., Ivanova K. A., Gerasimova S. V. Institute of Cytology and Genetics, SB RAS, Novosibirsk, Russia.

The purpose of this study was to evaluate the process of plant development in culture in vitro and the influence of various types of nutrient media on the regeneration processes of wild potatoes. Research data on optimal conditions for cultivation in vitro plants potato and their ability to regenerate can be used for genetic studies of the selection process when creating varieties with improved characteristics.

Key words: potato, wild species, cultivation, regeneration.

В работе был изучен 31 генотип диких видов картофеля (табл. 1). Культивирование in vitro осуществлялось посредством черенкования с применением питательной среды Мурасиге-Скуга [1]. Растения в асептических 
условиях разрезают по числу междоузлий, а черенки пересаживают в пробирки с питательной средой. Культивируют в течение четырех недель до следующего черенкования. Параметры роста отмечались через 10 и 20 дней после черенкования.

Таблица 1 - Список образцов in vitro коллекции диких видов картофеля

\begin{tabular}{|c|c|c|}
\hline № п/п & Вид & Номер каталога ВИР \\
\hline 1 & S. verrucosum & 23015 \\
\hline 2 & S. demissum & 15176 \\
\hline 3 & S. stoloniferum & 23652 \\
\hline 4 & S. polyadenium & 24957 \\
\hline 5 & S. pinnatisectum & 24239 \\
\hline 6 & S. ehrenbergii & 24207 \\
\hline 7 & S. pinnatisectum & 4455 \\
\hline 8 & S. pinnatisectum & 4455 \\
\hline 9 & S. pinnatisectum & 4459 \\
\hline 10 & S. pinnatisectum & 4459 \\
\hline 11 & S. pinnatisectum & 21955 \\
\hline 12 & S. stoloniferum & 3326 \\
\hline 13 & S. stoloniferum & 3360 \\
\hline 14 & S. stoloniferum & 3360 \\
\hline 15 & S. stoloniferum & 3554 \\
\hline 16 & S. jamesii & 24923 \\
\hline 17 & S. tarijense & 12637 \\
\hline 18 & S. pinnatisectum & 21955 \\
\hline 19 & S. cardiophyllum & 16828 \\
\hline 20 & S. pinnatisectum & 4459 \\
\hline 21 & S. pinnatisectum & 21955 \\
\hline 22 & S. pinnatisectum & 21955 \\
\hline 23 & S. pinnatisectum & 21955 \\
\hline 24 & S. pinnatisectum & 23569 \\
\hline 25 & S. pinnatisectum & 23569 \\
\hline 27 & S. dolichostigma syn S. chacoence & 7613 \\
\hline 28 & S. commersonii & 21355 \\
\hline 30 & S. fendleri & 18242 \\
\hline 33 & S. chacoense & 19759 \\
\hline 34 & S. chacoense & 22687 \\
\hline 35 & S. demissum & 15175 \\
\hline 36 & S. demissum & 19997 \\
\hline
\end{tabular}


Индукция регенерации осуществлялась в два этапа:

1. Посадка эксплантов в трех повторностях на питательную среду для индуцирования процесса образования каллуса (4,4 г/л MS, 2 мг/л глицина, 0,5 мг/л витамина В6, 1 г/л дрожжевого экстракта, 4 мг/л 2,4-Д, 25 г/л сахарозы и $0,8 \%$ агара, $\mathrm{pH}=5,6$ ). В качестве эксплантов использовали фрагменты междоузлий.

2. Пересадка эксплантов на различные экспериментальные питательные среды для морфогенеза и ризогенеза: (1) 4 г/л MS, 20 г/л сахарозы, 7 г/л агара, 6 мг/л глицина, 0,5 мг/л витамина В6, 2 мг/л 2,4-Д; (2) 2,2 г/л MS, 15 г/л сахарозы, 8 г/л агара, 0,2 мг/л гиббереллиновой кислоты, 0,1 мг/л кинетина; (3) 4,4 г/л MS, 20 г/л сахарозы, 8 г/л агара, 0,03 мг/л НУК, 30 мг/л БАП.

Результаты и обсуждение. При культивировании in vitro в течение 7 10 дней некоторые виды показывают существенную разницу в развитии растений (табл. 2). Высота растений варьируется от 0,63 до 4,27 см. Наибольшая высота растений отмечена у видов S. pinnatisectum (№ 5, 7) 4,1 см и 4,27 см. Также отмечены виды, имеющие наименьшую высоту растений, такие как S. pinnatisectum (№ 11) - 0,97 см и S. commersonii (№ 28) - 0,63 см.

На 10 день культивирования некоторые дикие виды картофеля не образуют корни, например, виды S. pinnatisectum (№ 10, 11) и $S$. commersonii (№ 28). Другие исследуемые виды к этому моменту образуют 1-2 корня.

При выращивании растений на 20 день отмечено, что дикие виды S. pinnatisectum (№ 21, 22) достигают 11,3 см в высоту. Наименьшая высота растений отмечена у видов $S$. commersonii (№ 28) и $S$. polyadenium (№ 4): 1,37 и 2,43 см соответственно.

Наибольшая длина корней отмечена у $S$. chacoense (№ 33), 7,43 см. Наименьшая длина отмечена у вида $S$. tarijense (№ 17) - 0,23 см.

Наибольшее количество корней отмечено у видов $S$. verrucosum (№ 1), S. pinnatisectum (№ 18) и S. dolichostigma (№ 27): 10, 11 и 14 корней соответственно. Развитие 1 корня наблюдается у вида $S$. pinnatisectum $(№ ~ 5,10)$. Вид S. commersonii (№ 28) не образует корней на 20 день культивирования.

Таблица 2 - Морфометрические показатели растений картофеля при культивировании в культуре in vitro

\begin{tabular}{|c|c|c|c|c|c|}
\hline \multirow{2}{*}{$\begin{array}{l}\text { № } \\
\text { ח/ா }\end{array}$} & \multirow{2}{*}{ Вид } & \multicolumn{2}{|c|}{ Высота растений, см } & \multirow{2}{*}{$\begin{array}{c}\text { Длина } \\
\text { корней, см }\end{array}$} & \multirow{2}{*}{$\begin{array}{l}\text { Количество } \\
\text { корней, шт. }\end{array}$} \\
\hline & & 10 дней & 20 дней & & \\
\hline 1 & 2 & 3 & 4 & 5 & 6 \\
\hline 1 & S. verrucosum & 2,60 & 10,90 & 3,70 & 10,3 \\
\hline 2 & S. demissum & 1,47 & 4,60 & 1,23 & 3,7 \\
\hline 3 & S. stoloniferum & 1,63 & 4,97 & 2,13 & 3,0 \\
\hline 4 & S. polyadenium & 1,27 & 2,43 & 1,77 & 3,0 \\
\hline 5 & S. pinnatisectum & 4,10 & 9,40 & 0,73 & 1,3 \\
\hline 6 & S. ehrenbergii & 2,63 & 6,50 & 1,20 & 5,0 \\
\hline 7 & S. pinnatisectum & 4,27 & 6,77 & 6,13 & 3,7 \\
\hline
\end{tabular}




\begin{tabular}{|c|c|c|c|c|c|}
\hline $\mathbf{1}$ & $\mathbf{2}$ & $\mathbf{3}$ & $\mathbf{4}$ & $\mathbf{5}$ & $\mathbf{6}$ \\
\hline 8 & S. pinnatisectum & 1,33 & 4,43 & 4,45 & 3,0 \\
\hline 9 & S. pinnatisectum & 2,70 & 7,13 & 1,67 & 2,3 \\
\hline 10 & S. pinnatisectum & 1,07 & 3,47 & 5,40 & 1,0 \\
\hline 11 & S. pinnatisectum & 0,97 & 4,00 & 2,60 & 2,0 \\
\hline 12 & S. stoloniferum & 2,10 & 7,30 & 3,67 & 4,0 \\
\hline 13 & S. stoloniferum & 2,93 & 11,07 & 1,77 & 4,7 \\
\hline 14 & S. stoloniferum & 3,33 & 10,53 & 3,97 & 5,7 \\
\hline 15 & S. stoloniferum & 3,27 & 9,77 & 3,87 & 5,0 \\
\hline 16 & S. jamesii & 1,35 & 9,12 & 3,56 & 3,8 \\
\hline 17 & S. tarijense & 1,37 & 3,83 & 0,23 & 4,3 \\
\hline 18 & S. pinnatisectum & 2,07 & 9,40 & 3,30 & 10,7 \\
\hline 19 & S. cardiophyllum & 3,33 & 7,33 & 0,83 & 4,0 \\
\hline 20 & S. pinnatisectum & 2,50 & 8,60 & 3,97 & 3,7 \\
\hline 21 & S. pinnatisectum & 2,33 & 11,30 & 6,70 & 3,7 \\
\hline 22 & S. pinnatisectum & 2,47 & 11,30 & 5,80 & 3,7 \\
\hline 23 & S. pinnatisectum & 2,07 & 7,83 & 5,73 & 4,0 \\
\hline 24 & S. pinnatisectum & 1,73 & 6,17 & 5,57 & 2,7 \\
\hline 25 & S. pinnatisectum & 3,10 & 8,20 & 6,27 & 4,0 \\
\hline 27 & S. dolichostigma & 1,20 & 7,63 & 4,47 & 13,7 \\
\hline 28 & S. commersonii & 0,63 & 1,37 & 0,00 & 0,0 \\
\hline 30 & S. fendleri & 1,50 & 10,07 & 7,10 & 5,7 \\
\hline 33 & S. chacoense & 3,43 & 9,80 & 7,43 & 6,7 \\
\hline 34 & S. chacoense & 1,27 & 2,10 & 2,67 & 4,7 \\
\hline 35 & S. demissum & 0,80 & 3,03 & 2,50 & 2,5 \\
\hline 36 & S. demissum & 1,93 & 5,70 & 2,97 & 3,0 \\
\hline & & & & & \\
\hline
\end{tabular}

В процессе индукции регенерации формирование каллуса отмечено у 26 диких видов картофеля. При применении различных питательных сред было отмечено, что наиболее оптимальной питательной средой для регенерации является вторая. При использовании питательной среды № 27 видов образовали побег, 5 видов - корень и 1 вид образовал и побег, и корень (табл. 3 ).

Таблица 3 - Процесс регенерации диких видов картофеля

\begin{tabular}{|c|c|c|c|c|c|}
\hline \multirow{2}{*}{$№$ п/п } & \multirow{2}{*}{ Вид } & \multirow{2}{*}{ Формирова- } & \multicolumn{2}{|c|}{ Регенерация, питательная среда } \\
\cline { 4 - 6 } & & ние каллуса & №1 & №2 & №3 \\
\hline $\mathbf{1}$ & $\mathbf{2}$ & $\mathbf{3}$ & $\mathbf{4}$ & $\mathbf{5}$ & $\mathbf{6}$ \\
\hline 1 & S. verrucosum & + & - & - & - \\
\hline 2 & S. demissum & + & $\mathrm{P}$ & $\mathrm{P}$ & $\mathrm{P}$ \\
\hline 3 & S. stoloniferum & + & - & - & - \\
\hline 4 & S. polyadenium & + & - & $\mathrm{P}$ & $\mathrm{P}$ \\
\hline 5 & S. pinnatisectum & + & - & $\mathrm{K}$ & - \\
\hline 6 & S. ehrenbergii & - & - & - & - \\
\hline 7 & S. pinnatisectum & + & - & $\mathrm{P}$ & $\mathrm{P}$ \\
\hline 8 & S. pinnatisectum & + & - & - & - \\
\hline
\end{tabular}




\begin{tabular}{|c|c|c|c|c|c|}
\hline $\mathbf{1}$ & $\mathbf{2}$ & $\mathbf{3}$ & $\mathbf{4}$ & $\mathbf{5}$ & $\mathbf{6}$ \\
\hline 9 & S. pinnatisectum & - & - & - & - \\
\hline 10 & S. pinnatisectum & + & $\mathrm{P}$ & - & - \\
\hline 11 & S. pinnatisectum & + & - & - & - \\
\hline 12 & S. stoloniferum & + & - & $\mathrm{K}$ & - \\
\hline 13 & S. stoloniferum & + & - & - & - \\
\hline 14 & S. stoloniferum & + & - & - & - \\
\hline 15 & S. stoloniferum & + & - & $\mathrm{K}$ & - \\
\hline 16 & S. jamesii & - & - & - & - \\
\hline 17 & S. tarijense & - & - & - & - \\
\hline 18 & S. pinnatisectum & + & $\mathrm{K}$ & - & $\mathrm{K}$ \\
\hline 19 & S. cardiophyllum & - & - & - & - \\
\hline 20 & S. pinnatisectum & + & - & - & - \\
\hline 21 & S. pinnatisectum & + & - & - & - \\
\hline 22 & S. pinnatisectum & + & $\mathrm{K}$ & $\mathrm{P}$ & - \\
\hline 23 & S. pinnatisectum & + & - & - & - \\
\hline 24 & S. pinnatisectum & + & - & $\mathrm{K}$ & $\mathrm{P}$ \\
\hline 25 & S. pinnatisectum & - & - & - & - \\
\hline 27 & S. dolichostigma & + & $\mathrm{P}$ & $\mathrm{P}$ & $\mathrm{P}$ \\
\hline 28 & S. commersonii & + & - & - & - \\
\hline 30 & S. fendleri & + & - & $\mathrm{P}$ & - \\
\hline 33 & S. chacoense & + & $\mathrm{K}$ & $\mathrm{P}, \mathrm{K}$ & $\mathrm{K}$ \\
\hline 34 & S. chacoense & + & - & $\mathrm{P}$ \\
\hline 35 & S. demissum & + & - & - & - \\
\hline 36 & S. demissum & + & - & - & - \\
\hline
\end{tabular}

+ - наблюдалось формирование каллуса, $P$ - наблюдалось формирование растений регенерантов, $K$-наблюдалось формирование корней без формирования побегов.

Заключение. В ходе исследования был изучен процесс культивирования in vitro растений диких видов картофеля с применением классической питательной среды Мурасиге-Скуга. Наиболее активно в культуре in vitro развиваются виды $S$. pinnatisectum, $S$. dolichostigma, $S$. chacoense, $S$. verrucosum.

Был охарактеризован процесс регенерации диких видов картофеля на различных питательных средах и выделена оптимальная питательная среда для процесса регенерации.

Благодарности: Работа выполнена при поддержке гранта РФФИ № 20-016-00217.

\section{Список литературь}

1. Murashige T. and Skoog F. (1962) A revised medium for rapid growth and bio-assays with tobacco tissue cultures. Physiol Plant. 15(3): 473-497. 